\title{
Efeitos de sentido sobre sexualidade e gênero nos discursos de crianças escolares
}

\author{
Student children sexuality and gender' effects of sense
}

Efectos de sentido sobre sexualidad y género en los discursos de niños escolares

Rafael De Tilio - Universidade Federal do Triângulo Mineiro - UFTM | Programa de Pós-Graduação em Psicologia da UFTM | Uberaba | MG | Brasil. E-mail: rafaeldetilio.uftm@gmail.com

Maria Teresa de Assis Campos - Universidade Federal do Triângulo Mineiro - UFTM | Professora do Departamento de Ciência Coletiva da UFTM | Uberaba | MG | Brasil E-mail: mtassiscampos@ hotmail.com

Luara Daisy Nascimento - Universidade Federal do Triângulo Mineiro - UFTM|Departamento de Psicologia Uberaba |MG | Brasil. Contato: luaradn@gmail.com (1) овсі

Resumo: A escola (atingida por práticas e políticas públicas relacionadas à sexualidade e gênero) possui papel preponderante enquanto possível reprodutora de tradicionalismos de gênero na formação da subjetividade das crianças. A fim de compreender alguns dos efeitos de sentido sobre sexualidade e gênero presentes em um contexto escolar foi realizada uma pesquisa qualitativa com entrevistas semiestruturadas e desenhos com sete estudantes do $3^{\circ}$ ao $5^{\circ}$ ano do ensino fundamental, de ambos os sexos, de uma escola pública de Uberaba/MG. A análise foi realizada a partir do referencial teórico da Análise do Discurso de Michel Pêcheux, cujos principais resultados destacaram a predominância de aspectos tradicionais de gênero (distintos para homens e mulheres) formulados em contextos extraescolares, reflexos de aspectos sociohistóricos e ideológicos de dominação e desigualdade entre os gêneros que perpassam o contexto escolar.

Palavras-Chave: Gênero. Análise do discurso. Escola.

Abstract: The school (affected by public policies about sexuality and gender) has a preponderant role as a possible reproducer of gender traditionalisms in the formation of children's subjectivity. To understand some effects of meaning on sexuality and gender present in a school, a qualitative study was conducted with semistructured interviews and drawings with seven students from the 3rd to 5th year of elementary school, of both sexes, on a public school of Uberaba/MG (Brazil). The analysis was based on the theoretical reference of Michel Pêcheux's Discourse Analysis, whose main results highlighted the predominance of traditional gender roles (distinct for men and women) formulated in extracurricular contexts, reflecting sociohistorical and ideological aspects of domination and inequality between the genres that permeate the school context.

Keywords: Gender. Discourse analysis. School.

Resumen: La escuela (afectada por prácticas y políticas públicas relacionadas a la sexualidad y género) tiene un papel preponderante como reprodutor de tradicionalismos de género en la formación de la subjetividad de los niños. A fin de comprender algunos de los efectos de sentido sobre sexualidad y género presentes en un contexto escolar se realizó un estudio cualitativo con entrevistas semiestructuradas y dibujos de siete estudiantes del 3 al 5 al año de la enseñanza fundamental de ambos sexos de una escuela pública de educación Uberaba/MG (Brasil). El análisis fue realizado a partir del referencial teórico del Análisis del Discurso de Michel Pêcheux, cuyos principales resultados destacaron la predominancia de aspectos tradicionales de género (distintos para hombres y mujeres) formulados en contextos extraescolares, reflejos de aspectos sociohistóricos e ideológicos de dominación y desigualdad entre los géneros que atravesan el contexto escolar.

Palabras clave: Género. Análisis del discurso. Escuela.

- Recebido em 11 de junho de 2019 • Aprovado em 12 de setembro de 2019 • e-ISSN: 2177-5796

DOI: http://dx.doi.org/10.22483/2177-5796.2019v21n3p745-766

Copyright @ 2019. Conteúdo de acesso aberto, distribuído sob os termos da Licença Internaonal da CreativeCommons - CC BY-NC-SA Atribuição Não Comercial (https://br.creativecommons.org/licencas/) - Permite distribuição e reprodução, desde que atribuam os devido créditos à publicação, ao autor(es) e que licenciem as novas criações sob termos idênticos. 
DE TILIO, Rafael; CAMPOS, Maria Teresa de Assis; NASCIMENTO, Luara Daisy. Efeitos de sentido sobre sexualidade e gênero nos discursos de crianças escolares.

\section{Introdução}

A escola é uma instituição social de educação formal, de formação de sujeitos e de socialização que, como aparelho ideológico do Estado, possui papel preponderante enquanto possível reprodutora de determinações de gênero na formação da subjetividade das crianças e dos adolescentes. Nela, alguns aspectos podem ser observados sobre as relações de poder entre e intragêneros, como: "a normalização da conduta dos meninos e meninas, a produção dos saberes sobre a sexualidade e os corpos, as táticas e as tecnologias que garantem o 'governo' e o 'autogoverno' dos sujeitos” (LOURO, 2003, p. 42).

Andrade (2010) remonta o histórico internacional e brasileiro sobre os direitos da infância abordando a Constituição de 1988, a LDB de 1996 e o ECA de 1990, enquanto importantes marcos legais que reconhecem os direitos da infância e da criança como sujeito de direitos. A escola tem o dever de viabilizar o acesso à formação básica, educação, igualdade, direitos e construção da cidadania, bem como ouvi-la e atendê-la em suas necessidades e especificidades. Assim, o sistema público de ensino no Brasil se organiza de modo a garantir a educação básica desde o início da vida até os dezessete anos de idade, sendo divididas as atribuições entre União, Estados e Municípios.

A combinação entre sexualidade, gênero e escolarização formal permeia as escolas a partir de diversas práticas e políticas públicas que potencialmente contribuem para uma (re) produção de discursos que demarcam os espaços de atuação do feminino e do masculino, impactando a formação das subjetividades e dos sujeitos. Muitos projetos e iniciativas envolvendo gênero e sexualidade nas escolas vêm sendo desenvolvidas e discutidas ao longo da história da educação no Brasil, configurando um panorama controverso ${ }^{1}$ (CÉSAR, 2009; MISKOLCI; CAMPANA, 2017).

Borges e Borges (2018) argumentam sobre a "ideologia de gênero" e da demanda por uma "escola sem partido" que vêm sendo amplamente utilizadas em discursos políticos e religiosos a partir da convicção de que discussões sobre gênero e sexualidades não-heteronormativas nas escolas constituem uma ameaça aos tradicionalismos e a estrutura familiar idealizadas (nuclear e

\footnotetext{
${ }^{1}$ Essas discussões se concentram em torno da tríade temática da escola sem homofobia (pejorativamente denominada de kit gay), da ideologia de gênero e da escola sem partidos. Sobre a Escola Sem Partido conferir o recente dossiê publicado pela Quaestio - Revista de Estudos em Educação em 2018.
} 
DE TILIO, Rafael; CAMPOS, Maria Teresa de Assis; NASCIMENTO, Luara Daisy. Efeitos de sentido sobre sexualidade e gênero nos discursos de crianças escolares.

heterossexual). As autoras afirmam que com isso há uma tendência à supressão destes temas nos projetos pedagógico e nos planos de ensino, sendo obnubiladas as discriminações, exclusões e violências que decorrem da pouca discussão e debate.

Em contrapartida, há importantes iniciativas que visam diminuir as desigualdades sociais, incluindo as de gênero/sexualidade. Os Parâmetros Curriculares Nacionais pretendem inserir temáticas de relevância sociais, incluindo a equidade de gênero, nos conteúdos curriculares. $\mathrm{O}$ Plano Nacional de Educação (PNE) propõe ações e de metas visando a:

Consolidação de política direcionada a um projeto político-pedagógico participativo, que tenha como fundamento: a autonomia, a qualidade social, a gestão democrática e participativa e a diversidade cultural, étnico-racial, de gênero, do campo (SOUSA; GRAUPE, 2014, p. 5).

A Lei de Diretrizes e Bases da Educação Brasileira - LDB orienta sobre a necessidade do estabelecimento de condições favoráveis para efetivar os direitos de acesso e permanência na escola para todos - todavia, o conceito de gênero não foi mencionado neste dispositivo legal (AVILA; TONELI; ANDALÓ, 2011; SOUSA; GRAUPE, 2014).

Por isso, a discussão sobre sexualidade e gênero ocorre a partir de pontos de vista antagônicos, sendo necessárias investigações a fim de possibilitar a transformação social (compreendida em seu sentido amplo de conscientização) a partir de uma educação igualitária e equânime. Campos (2015), Maia et al. (2012) e Mosconi (2014) afirmam ser importante refletir e intervir sobre as questões de gênero e sexualidade nas escolas a fim de combater o sexismo, transhomofobia e violência no interior e no exterior destas instituições. E uma das maneiras para investigar se as escolas cumprem com essa finalidade é por meio dos discursos das crianças naquele contexto. Louro (2003) inspira esta pesquisa ao afirmar que "Estudiosas e estudiosos das desigualdades de gênero, ao combinarem o rigor das análises com o entusiasmo das lutas sociais, nos fazem pensar que as formas de opressão e a instituição das diferenças são muito mais do que temas acadêmicos de ocasião - elas se constituem em apaixonante questão política” (p. 55).

Assim, este artigo tem como objetivo compreender alguns dos efeitos de sentido sobre sexualidade e gênero presentes num contexto escolar. 


\section{Aspectos Metodológicos}

Esta é uma pesquisa qualitativa, exploratória e transversal.

Participaram sete crianças com idade entre oito e onze anos, de ambos os sexos, frequentando (em 2018) entre o $3^{\circ}$ e $5^{\circ}$ ano do ensino fundamental (EF) de uma instituição escolar pública de Uberaba/MG, em ano escolar correspondente à faixa etária. São eles: E1, mulher, 8 anos de idade, cursando o $3^{\circ}$ ano do EF; E2, mulher, 8 anos, cursando o $3^{\circ}$ ano do EF; E3, mulher, 9 anos, cursando o $4^{\circ}$ ano do EF; E4, mulher, 9 anos, cursando o $4^{\circ}$ ano do EF; E5, homem, 9 anos, cursando o $4^{\circ}$ ano do EF; E6, homem, 9 anos, cursando o $4^{\circ}$ ano do EF; E7, homem, 11 anos, cursando o $5^{\circ}$ ano do EF.

Essa pesquisa foi aprovada pelo Comitê de Ética em Pesquisa da universidade dos pesquisadores (CAAE 87866618.1.0000.5154 na Plataforma Brasil).

Os dados foram obtidos a partir de entrevistas semiestruturadas e de desenho livre como procedimento complementar. A entrevista semiestruturada abordava aspectos sobre o cotidiano escolar e sobre relações de gênero. Após a entrevista foi solicitado um desenho livre seguindo de explicação sobre o que a criança mais gostava na escola ${ }^{2}$.

Primeiramente houve o contato com os gestores da escola para autorização da coleta. $\mathrm{O}$ recrutamento ocorreu no horário de saída da escola, momento em que os responsáveis e crianças eram abordados pelos pesquisadores que lhes explicavam a proposta de pesquisa e solicitava o aceite de ambos. Foram abordados 15 responsáveis e crianças, mas apenas sete concordaram em participar; nestes casos, a entrevista era agendada. As entrevistas individuais ocorreram nas dependências da escola e foram audiogravadas, posteriormente transcritas integral e literalmente para análise de dados.

Os dados foram analisados segundo o referencial teórico da Análise do Discurso de linha francesa de Michel Pêcheux.

A Análise do Discurso (AD) define o discurso como efeito(s) de sentidos entre interlocutores, permitindo identificar as regularidades na compreensão de seu funcionamento, considerando o sujeito interpelado pelo contexto histórico e social bem como determinado pela ideologia e pelo inconsciente (PÊCHEUX, 2014). Assim, é fundamental considerar as condições

\footnotetext{
${ }^{2}$ Desenho livre sem qualquer lastro de testes psicológicos seja em sua concepção, aplicação e/ou interpretação. 
DE TILIO, Rafael; CAMPOS, Maria Teresa de Assis; NASCIMENTO, Luara Daisy. Efeitos de sentido sobre sexualidade e gênero nos discursos de crianças escolares.

materiais (contexto) imediatas (circunstâncias da enunciação) e amplas (sociohistóricas e ideológica) de produção dos sentidos.

Alguns conceitos são importantes neste referencial teórico. O intradiscurso é o propriamente dito/proferido, enquanto o interdiscurso é a memória discursiva (referente àquilo que permeia e condiciona os discursos). O interdiscurso permite vincular sentidos aos sujeitos em sua historicidade, sendo possível compreender suas determinações políticas e ideológicas (ORLANDI, 2013). O Esquecimento Número 2 (PÊCHEUX, 2014) remete à ilusão de que o que foi dito só poderia ser feito daquela exata maneira, havendo equívoco de correspondência entre pensamento e enunciação. O Esquecimento Número 1 (PÊCHEUX, 2014) trata da ilusão de autoria do sujeito acerca do que diz, como se fosse ele (e não os aspectos ideológicos) a origem dos sentidos. A Formação Discursiva (FD) (na qual é possível perceber a atuação do interdiscurso e do Esquecimento Número 2) é aquilo "o que pode e deve ser dito" (PÊCHEUX, 2014, p. 160) em uma determinada Formação Ideológica (FI) e conjuntura sociohistórica que circunscrevem o sujeito. Portanto, é por meio das FD que podem ser compreendidas as regularidades no funcionamento dos discursos e dos sentidos (MARTINS, 2011; PÊCHEUX, 2014). A Formação Ideológica (FI) evidencia que o sentido (de um discurso) é determinado interdiscursivamente pelas posições ideológicas em um processo sociohistórico, controlando e influenciando as possibilidades de sentido das FD (PÊCHEUX, 2014). Por fim, as Formações Imaginárias (FImag) se referem às relações de sentido (discursos se correlacionam produzindo sentidos), às relações de força (posições que o sujeito ocupa na sociedade) e às antecipações (de sentido do lugar do interlocutor), as quais o sujeito articula inconscientemente (ORLANDI, 2013).

Gomes (2007) e Orlandi (2013) explicitam o percurso metodológico da AD. Primeiramente se deve passar da superfície linguística (no caso desta pesquisa, o arquivo de entrevistas transcritas e de desenhos) para os objetos discursivos (trechos selecionados das entrevistas e desenhos) que estão atrelados à específicas FD. Depois, dos objetos discursivos se passa para a análise do processo discursivo, ou seja, a compreensão das relações entre as FD e a FI.

\section{Resultados e discussão}

A apresentação dos resultados e discussão segue em duas partes. Primeiro são dispostos os objetos discursivos atrelados a uma ou mais FD. Foram destacadas as seguintes FD: FD1 
DE TILIO, Rafael; CAMPOS, Maria Teresa de Assis; NASCIMENTO, Luara Daisy. Efeitos de sentido sobre sexualidade e gênero nos discursos de crianças escolares.

Preferências e Habilidades, FD2 Socialização e FD3 Condutas, para cuja análise foram mobilizados os conceitos de interdiscurso, Esquecimento Número 2, bem como outros dispositivos analíticos - paráfrase (diferentes formulações acerca de um mesmo dizer) e polissemia (deslocamento e ruptura de processos de significação). No segundo momento é discutido o processo discursivo, para cuja analise foram mobilizados os conceitos de FD e FI (ORLANDI, 2013; PÊCHEUX, 2014).

Para melhor circunscrever a discussão é significativo destacar as condições de produção dos discursos dos participantes: são crianças que falam do lugar de sua faixa etária e de desenvolvimento (entre 8 e 11 anos); são estudantes de um ambiente escolar específico; são respondentes de uma entrevista sobre gênero e sexualidade relacionadas àquele contexto. Ademais, há um contexto amplo (escola) tanto institucional (provido de especificidades em sua estrutura, mecanismos e formas de organização) quanto sociohistórico e ideológico (a função da escola na formação dos indivíduos).

\subsection{Formações discursivas}

Os objetos discursivos (OD) apresentados são recortes da superfície linguística do arquivo de entrevistas transcritas e desenhos produzidos pelos participantes. Na FD1 foram estabelecidos seis OD; na FD2 foram estabelecidos dez OD; e na FD3 foram estabelecidos onze OD.

\subsubsection{FD1: Preferências e habilidades}

Bastante presente nas entrevistas foram as distinções entre preferências e habilidades relacionados aos gêneros. Foi recorrente a dualidade entre meninos brincarem de bola/jogarem futebol enquanto meninas brincarem de boneca ou outras brincadeiras, inclusive perpassando as aulas de educação física nas quais meninos e meninas jogam/brincam atividades diferentes e em separados. Monteiro (2017) aponta para a importância das aulas de educação física na construção identitária das crianças, haja vista que essas aulas são interpeladas pelo conjunto de experiências e construções sociais referentes aos gêneros. $\mathrm{O}$ autor discorre sobre preconcepções de atividades e brincadeiras envolvendo atividades físicas em que há juízos sobre o que é considerado 
DE TILIO, Rafael; CAMPOS, Maria Teresa de Assis; NASCIMENTO, Luara Daisy. Efeitos de sentido sobre sexualidade e gênero nos discursos de crianças escolares.

adequado para meninos e meninas ou o que cada qual é capaz e deve preferir, pautados em distinções e estereótipos de sexo/gênero. O OD $1^{3}$ ilustra isso:

OD 1: (pergunta-se acerca da interação entre meninos e meninas na aula de educação física).

Eles não brincam com as meninas. Os menino mais brinca de futebol e as menina fica no canto delas, brincando lá... de ginástica, lá no... no tatame assim. (E4)

Pergunta: O que você acha disso?

Normal, porque toda as escola que eu estudei era assim. (E4)

Pergunta: Por que você acha que acontece assim?

Porque... os menino gosta mais de brinca de bola e as menina de outras brincadeiras diferentes. (E4)

Neste trecho é possível notar uma relação de sentido (ORLANDI, 2013; PÊCHEUX, 2014) entre duas FD (FD1 e FD2, esta última explorada na próxima seção) em que as preferências estão atreladas à socialização distinta para os gêneros. São abordadas distinções de gênero acerca das preferências por jogos e brincadeiras específicos, ficando meninas e meninos separados nas aulas de educação física. Da influência do interdiscurso (ORLANDI, 2013; PÊCHEUX, 2014) pode-se inferir uma memória discursiva acerca dos posicionamentos de gênero que circunscrevem a menina (gênero feminino) e o menino (gênero masculino) nestas determinadas posições e preferências, sendo que o OD 1 corrobora com representações e práticas tradicionais de gênero (BICHARA, 2001; RIBEIRO, 2006). Ainda, a participante destacou a distinção entre meninos e meninas com o uso da palavra "normal", remontando ao Esquecimento Número 2 (ORLANDI, 2013; PÊCHEUX, 2014), sendo somente esta palavra cabível e não outra (como, por exemplo, "frequente" ou "recorrente"), de forma a indicar uma naturalização destes papéis.

Pylro e Rossetti(2005) discutem acerca das práticas lúdicas envolvendo relações de gênero, havendo considerações pautadas nos aspectos biológicos, nas pressões sociais e nos interesses recreativos, recorrentemente regidos por estereotipias. Corroborando com esta ideia apareceu a suposição de que a menina não possui habilidades ou competências para atividades

\footnotetext{
${ }^{3}$ Para manter a fidedignidade (e possíveis efeitos de sentidos) a transcrição dos discursos é literal. 
DE TILIO, Rafael; CAMPOS, Maria Teresa de Assis; NASCIMENTO, Luara Daisy. Efeitos de sentido sobre sexualidade e gênero nos discursos de crianças escolares.

consideradas masculinas - resultado da ação do interdiscurso (ORLANDI, 2013; PÊCHEUX, 2014), conforme ilustra o OD 2:

OD 2: Pergunta: Por que você acha que os meninos jogam futebol e as meninas outras brincadeiras?

É porque... por causa que os menino, eles fica jogando e as menina não sabe brincar de futebol. Aí... eles joga a bola pro alto e as menina não sabe nem chutar. Só isso. (E2)

Ao afirmar que a menina "não sabe" brincar de futebol pressupõe-se que esta não é uma habilidade própria ou natural das meninas, especificando que elas não sabem "nem" chutar, reiterando sua incompetência ou incapacidade. Nisto se percebe o Esquecimento Número 2 (ORLANDI, 2013; PÊCHEUX, 2014), pois ao ser dito daquela maneira e não de outra (por exemplo, que não atrelada ao gênero, tal como dizer que a menina não "pratica" ou não tem "experiência" em tal atividade pressuporia ser ela capaz de aprender a jogar futebol) são produzidos específicos efeitos de sentido. Reiterando estas concepções infere-se a ideia de que há algo natural nos meninos relacionado ao futebol em um interesse e predileção natos para tal atividade (OD 3):

OD 3): Pergunta-se como são as aulas de educação física.

Pros meninos é a melhor aula, porque eles... joga futebol, eles gostam de brincar. A, eu gosto de brinca... de vôlei, essas coisas e quando a gente tá cansada, a gente brinca de tampinha... e montar coisas, essas coisas. (E3)

Pergunta: Por que você acha que pros meninos é a melhor aula?

Porque... toda hora, igual na escola, eles tão pensando em futebol. Aí... na entrada eles joga futebol. Não, não. Na saída. Porque na entrada não pode. E na ... educação fisica. Porque eles adoram, sabe. (E3)

"Para os meninos é a melhor aula" destaca que a aula tem caráter de interesse para os meninos, sendo considerada a melhor aula para este público, pois é tido como inerente a eles "pensar[em]" e "adorar[em]" futebol, demonstrando o padrão de interesses e preferências atrelados ao gênero - interdiscurso (ORLANDI, 2013; PÊCHEUX, 2014). Em contrapartida, algumas respostas demonstraram um deslocamento (paráfrase) de sentido (ORLANDI, 2013; PÊCHEUX, 2014) possibilitado pelo interdiscurso. Os OD 4 a 6 partiram do princípio das tradicionalidades, mas as revisitaram. Ao serem questionados se haveria brincadeiras só para meninos, brincadeira só para meninas e brincadeira para ambos, os participantes responderam: 
DE TILIO, Rafael; CAMPOS, Maria Teresa de Assis; NASCIMENTO, Luara Daisy. Efeitos de sentido sobre sexualidade e gênero nos discursos de crianças escolares.

OD 4:

É... as pros dois... pode ser... pique-pega ou pique-esconde... essas brincadeiras. Agora só pras meninas, só pros meninos, não sei. Aí eu não sei. (E1)

Pergunta: Por que você acha que essas que você me falou são pros dois?

Porque... não precisa ser só as meninas que tem que... tipo, jogar só pique-pega... ou só pique-esconde... (E1)

\section{OD 5:}

Eu acho que brincadeira pros dois, porque as meninas também podem jogar futebol, os meninos também podem brincar de boneca ... essas coisas. (E3)

OD 6:

Pros dois. Tipo, as menina pode jogar bola, os menino pode brincar de boneca... não é nada proibido. (E5)

Pergunta: Por que você acha isso?

Porque... tipo... por que você não vai, você não pode... por que as menina não pode joga bola? É chuta a bola. Qualquer pessoa pode. Tem menino que fala: as menina não pode joga bola. Eu, eu... disconcordo. Eu acho que as menina pode jogar bola. Todo mundo tem que diverti. (E5)

Em um movimento de paráfrase (ORLANDI, 2013; PÊCHEUX, 2014) são percebidas diferentes formulações que remontam ao mesmo núcleo de sentido. E1 fez o uso do verbo "tem", E3 disse "podem" e E5 articulou que "nada é proibido" - todos se referindo a uma regra/obrigatoriedade dos papéis de gênero. Ainda que contrários a estas regras, partem delas e as alocam em seus discursos, utilizando estas palavras e não outras que as reafirmam (Esquecimento Número 2). Por exemplo, E1 fez uma tentativa de contrapor o que está sedimentado, mas escolheu como jogos possíveis para ambos os gêneros aqueles que os tradicionalmente permitem; E5 fez um apontamento interessante ao dizer "É chuta a bola. Qualquer pessoa pode", jogando com o equívoco e com o conceito de polissemia (ORLANDI, 2013; PÊCHEUX, 2014), desconstruindo a ideia do futebol enquanto prática restrita ao gênero masculino. E5 também disse que "todo mundo tem que diverti" pressupondo que a diversão não deveria depender de papéis de gênero. E ao dizer "disconcordo" contraria o consenso que está sedimentado no interdiscurso (ORLANDI, 2013; PÊCHEUX, 2014) - que as meninas não podem jogar bola, pois discorda daquilo que é concordado no interdiscurso (ORLANDI, 2013; PÊCHEUX, 2014). 
DE TILIO, Rafael; CAMPOS, Maria Teresa de Assis; NASCIMENTO, Luara Daisy. Efeitos de sentido sobre sexualidade e gênero nos discursos de crianças escolares.

\subsubsection{FD2: Socialização}

A distinção de gênero é uma característica típica do modo de socializar da infância. Em geral e mais frequentemente meninos e meninas brincam com seus iguais, havendo formas específicas de brincar de acordo com estereótipos de gênero (CORDAZZO; VIEIRA, 2008; BOYD; BEE, 2011; LEITE; FEIJÓ; CHIÉS, 2016).

Os participantes apontaram uma socialização mais frequente com amigos do mesmo gênero. Ao serem questionados acerca de terem na escola mais amizade com meninos ou com meninas, relataram (OD 1 a 3):

OD 1:

Meninas. (E1)

Pergunta: Me conta um pouquinho sobre isso

Sempre a gente fica... a gente sempre anda junto com as meninas e os meninos sempre fica com os meninos. As meninas sempre brincam com as meninas e os meninos sempre brincam com os meninos. (E1)

OD 2:

Meninos. (E5)

Pergunta: Por que você acha que tem mais amigos meninos?

Porque... na educação física, eu jogo mais bola ... convivo mais com as meninas no recreio também... (E5)

OD 3:

Sou mais amigo dos meninos. Porque tem mais menino. Não, tem mais menina, mas eu gosto mais dos meninos. (E6)

Pergunta: Por que você acha que gosta mais dos meninos?

Ah... meu estilo né. Sou homem... aí... né. (E6)

Dessa perspectiva, considerando as influências do interdiscurso (ORLANDI, 2013; PÊCHEUX, 2014) E1 ao dizer "sempre" evoca o consenso de que as relações entre pares precisam ser desta maneira (meninos com meninos, meninas com meninas), ou seja, instaura a obrigatoriedade. Ainda é possível notar uma naturalização desta forma de socializar. E6 reiterou esta concepção ao dizer "meu estilo", subentendo o universo masculino enquanto meio de identificação entre pares. No discurso de E5 é possível notar uma relação de sentido (ORLANDI, 
DE TILIO, Rafael; CAMPOS, Maria Teresa de Assis; NASCIMENTO, Luara Daisy. Efeitos de sentido sobre sexualidade e gênero nos discursos de crianças escolares.

2013; PÊCHEUX, 2014) entre duas FD (FD1 e FD2) em que as preferências e habilidades e a socialização estão correlacionadas, pois E5 apontou a identificação por jogar bola como atividade tipicamente masculina, e referiu o convívio com as meninas como uma aproximação circunstancial no recreio.

Boyd e Bee (2011) caracterizam o perfil das amizades entre meninos e entre meninas apontando para o fato de que, em geral, grupos de meninas costumam ser mais conciliadores e obedientes, enquanto grupos de meninos tendem a ser mais competitivos e dominadores, denotando características socializatórias pautadas nas diferenças entre os gêneros. Nos seguintes excertos (OD 4 e 5) é possível notar uma relação de sentido entre duas FD (FD2 e FD3, a ser discutida na próxima seção) em que a socialização se atrela as condutas de gênero:

OD 4:

Com meninas. (E2)

Pergunta: Me conta um pouquinho sobre isso.

Os meninos... eles são... mais bagunceiros. As menina são mais um pouco quietinhas. (E2)

OD 5:

Eu acho que com meninas. (E3)

Pergunta: E porque você acha que isso acontece?

Hm... porque... os meninos sempre estão correndo... essas coisas. (E3)

Meninos bagunceiros e meninas quietinhas são características que aparecem de modo a demarcar padrões considerados convencionais de conduta do masculino e do feminino interdiscurso (ORLANDI, 2013; PÊCHEUX, 2014) - e que regulam a identificação e a aproximação nas relações sociais. Pode-se inferir também que as condutas esperadas para meninas e meninos interpelam as relações sociais visando manter estas condutas. E3 representou esta suposição ao explicar que os meninos estão sempre correndo, conduta esperada dos meninos, porém, não apropriada para meninas.

Os desenhos solicitados (OD 6 a 9) sobre o que mais gostavam na escola serviram como material complementar às entrevistas: 
DE TILIO, Rafael; CAMPOS, Maria Teresa de Assis; NASCIMENTO, Luara Daisy. Efeitos de sentido sobre sexualidade e gênero nos discursos de crianças escolares.

Figura 1 - OD 6

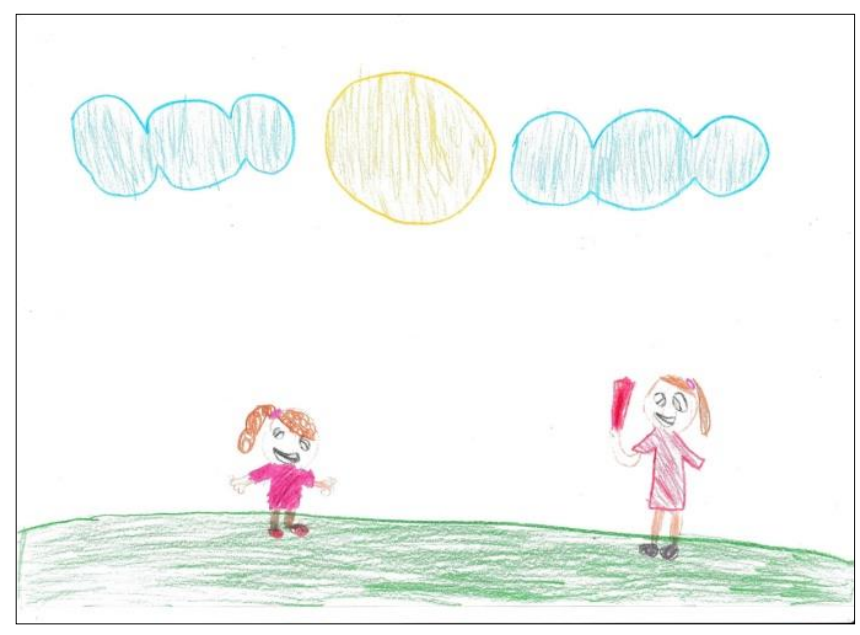

Fonte: E1

Figura 2 - OD 7

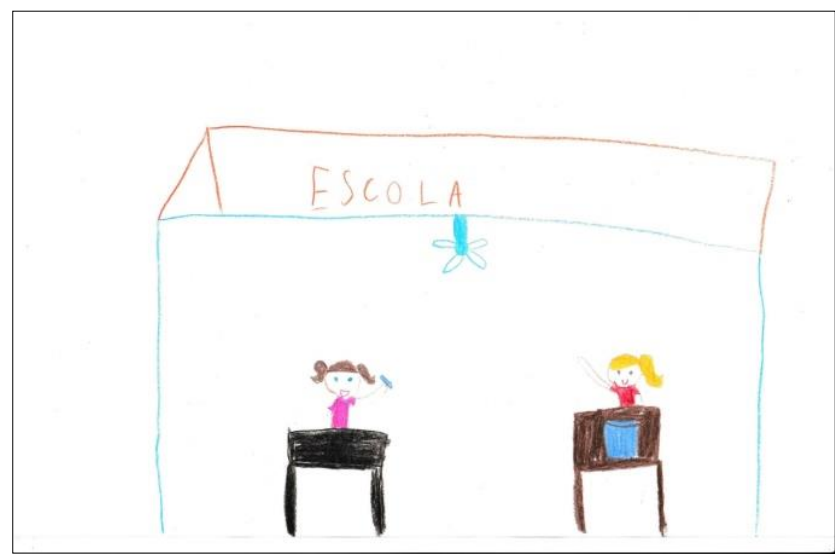

Fonte: E2

Figura 3 - OD 8

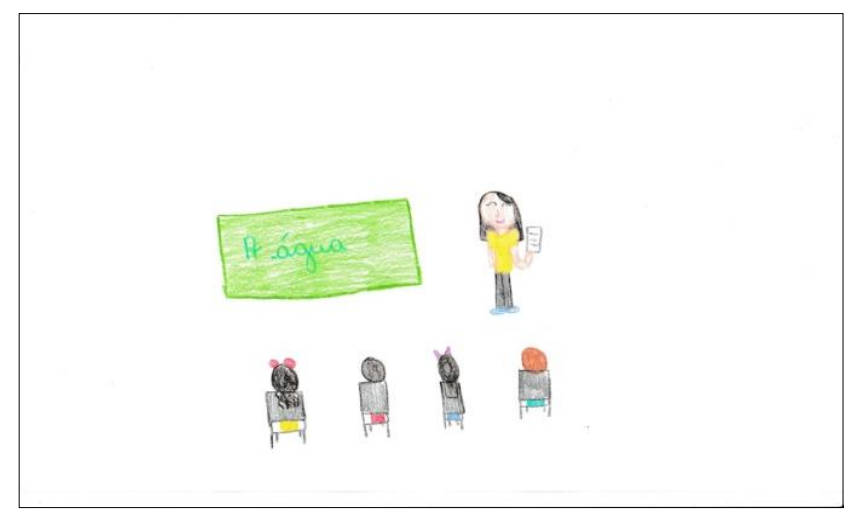

Fonte: E3

Quaestio, Sorocaba, SP, v. 21, n. 3, p. 745-766, set./dez. 2019. 
DE TILIO, Rafael; CAMPOS, Maria Teresa de Assis; NASCIMENTO, Luara Daisy. Efeitos de sentido sobre sexualidade e gênero nos discursos de crianças escolares.

Figura 4 - OD 9

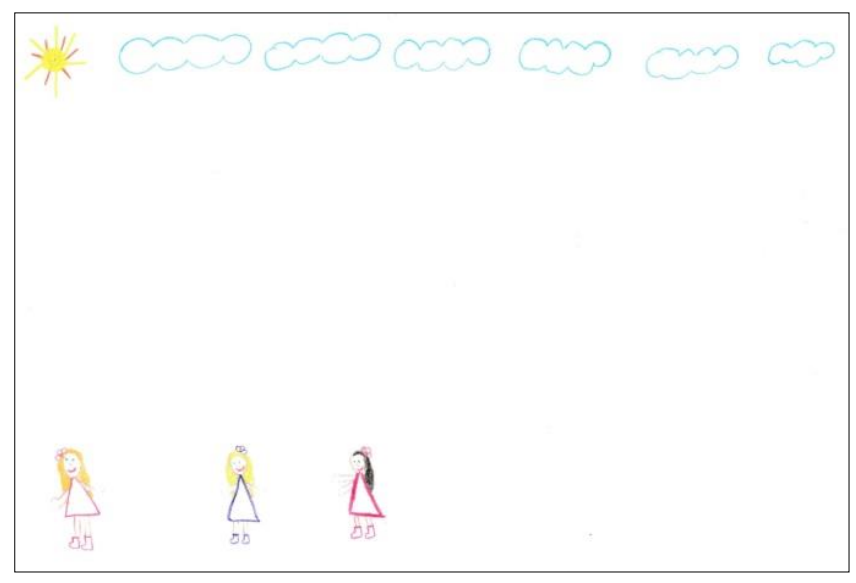

Fonte: E4

Nos desenhos de E1, E2 e E4 é possível notar que foram representadas meninas brincando ou estudando somente com outras meninas, corroborando com o já discutido. Apareceu ainda uma relação com as condutas (FD3) do universo feminino em que três desenhos as meninas foram representadas com vestimentas tons de rosa, vermelho e roxo, bem como com laços no cabelo - evidenciando o padrão da aparência típica feminina. E3 desenhou quatro crianças assistindo a aula, sendo duas meninas e dois meninos intercalados (contrariando a socialização dentre crianças do mesmo sexo); contudo, as figuras foram representadas de costas e diferenciadas pelos cabelos longos com laço no topo da cabeça (meninas) e cabelo curto (meninos), mantendo o tradicionalismo quanto à aparência.

Por fim, o OD 10 retoma a questão da socialização dentre iguais (FD2), bem como das preferências assentadas nos papéis de gênero (FD1), interpelando vontades, atividades e constituição do brincar:

OD 10:

Pergunta: Você já deixou de fazer alguma atividade na escola por que você é menina?

Não. Só, eu não jogo futebol porque minhas amigas... não brincam, sabe. Ai eu ... eu brinco com elas. (E3)

Pergunta: E se elas brincassem?

Eu acho que eu brincaria. (E3)

E3 respondeu negativamente à pergunta, mas contrariamente relatou algo que deixou de fazer por ser menina. Então, percebe-se a retomada do que está sedimentado acerca do brincar 
DE TILIO, Rafael; CAMPOS, Maria Teresa de Assis; NASCIMENTO, Luara Daisy. Efeitos de sentido sobre sexualidade e gênero nos discursos de crianças escolares.

entre os do mesmo sexo - interdiscurso (ORLANDI, 2013; PÊCHEUX, 2014). Se há o pressuposto de uma atividade praticada entre meninos não seria possível ter deixado de fazer algo que não cabe a priori ao universo das brincadeiras femininas - por isso respondeu negativamente à pergunta. Contudo, trabalhando com o equívoco, justificou a negativa ao apontar para o fato de que, contrariando a regra, jogaria futebol.

\subsubsection{FD3: Condutas}

Foi presente nas entrevistas um imaginário acerca do universo masculino e feminino marcado por diferenças de condutas, comportamentos e características físicas e psíquicas específicos e típicos de cada um - remontando ao que está consolidado e possibilitado pelo interdiscurso (ORLANDI, 2013; PÊCHEUX, 2014). Foi possível notar as influências das Formações Imaginárias (ORLANDI, 2013; PÊCHEUX, 2014) tendo em vista o lugar do interlocutor demarcado pelo feminino e/ou pelo masculino - isto é, o interlocutor tenta antecipar (a constituição dos) sentidos a partir da imagem que tem de si e do outro a partir do lugar que ocupa no universo masculino e/ou feminino. Assim, a partir da pergunta "você acha que meninos e meninas são diferentes?” alguns participantes responderam (OD 1 a 3):

OD 1:

São diferentes pela aparência. (risos) Pelo cabelo, pela cor... Mas essas coisas de brincar não. (E5)

OD 2:

Sim. (E7)

Pergunta: Como eles são diferentes?

Por causa do banheiro. As menina... mija sentada e os menino mija em pé. Não sei... É, a cara ... o peito... essas coisa. (E7)

OD 3:

Ai... até que um pouco. Porque... eles não tem a mesma aparência, ninguém tem assim. Uma menina também pode parecer com uma menina e um menino não vai parecer com uma menina. Porque dá pra ver que é um menino. Igual, não tem como uma menina ficar igual a um menino. Então não parece. Até por dentro pode até parecer assim. Ser caridoso, bondoso... Pode até parecer. (E4) 
DE TILIO, Rafael; CAMPOS, Maria Teresa de Assis; NASCIMENTO, Luara Daisy. Efeitos de sentido sobre sexualidade e gênero nos discursos de crianças escolares.

Maia (2005) argumenta que os estereótipos sexuais são padrões rígidos de gênero que ocorrem em diferentes culturas e momentos históricos, estabelecendo características específicas para homens e mulheres em função do sexo (biológico). E5 e E7 apontaram para diferenças de aparência física entre meninos e meninas. Contudo, E5 significou a aparência não necessariamente atrelada aos estereótipos sexuais - pela referência ao cabelo e cor. Em contraponto, E7 situou a diferenciação sexual ao destacar os aspectos genitais pela forma que cada um utiliza o banheiro, bem como da fisionomia e biotipo de cada um. E4 tentou "controlar" a deriva dos sentidos interdiscursivamente operantes reiterando concepções cristalizadas acerca do feminino e do masculino - interdiscurso (ORLANDI, 2013; PÊCHEUX, 2014) e ao se deparar com equívocos e falhas reformulou o que disse contrapondo as diferenças físicas (considerando a aparência típica de menina e de menino) denotando que o sexo e a expressão de gênero deveriam ser coincidentes - conforme predominantemente firmado na sociedade, ou seja, pelo interdiscurso (ORLANDI, 2013; PÊCHEUX, 2014). Por fim, contrapôs os aspectos psíquicos, alegando que neste nível um homem pode ter características de uma mulher, sendo aceitável ser "bondoso" ou "caridoso".

Ainda acerca dos aspectos físicos diante da pergunta sobre como se vestiam para ir à escola, seguem os OD 4 e 5:

\section{OD 4:}

Bom, como... é... como agora e sempre, eu gosto de vim com a roupa da escola, que eu acho bem confortável. Eu não gosto de vim com aquele short curto... As coisas que não pode vim pra escola. E... quando não tem uniforme, quando minha mãe... é... ou quando tá sujo ele de comida, eu gosto de vim com uma blusa branca, porque... essas roupas, é, não é, é... as roupas de sair, não é muito adequada com a escola. (E3)

OD 5:

Hm, fechada. (E2)

Pergunta: Fechada? Como é fechada?

É... não com roupa curta. (E2)

Pergunta: E por quê?

Porque eu acho feio. (E2) 
DE TILIO, Rafael; CAMPOS, Maria Teresa de Assis; NASCIMENTO, Luara Daisy. Efeitos de sentido sobre sexualidade e gênero nos discursos de crianças escolares.

Pergunta: O que você acha feio?

As menina vem de shorts curto, é... batom escuro... só. (E2)

Mosconi (2014) destaca que estes estereótipos direcionam expectativas e condutas, sendo que esses aspectos são produzidos sem que os sujeitos estejam conscientes disso. Assim, quando E3 disse do que "não pode" e do que é "adequado" ao seu sexo/gênero isso está remetido à regra em relação à vestimenta no contexto escolar, corroborando ao dizer que "não gosta" de ir com o short curto. Estas colocações representam o que está cristalizado em normas acerca do vestuário feminino, subentendendo, inclusive, condutas e os "bons modos" esperados das mulheres interdiscurso (ORLANDI, 2013; PÊCHEUX, 2014). E2 também trouxe a questão do short curto e do batom escuro, remontando ao imaginário do que é ou não adequado e aceitável no contexto escolar, bem como pressupondo uma postura inadequada ao modo (sensualizado) de vestir. Ainda, quando E2 utilizou a palavra "fechada" ela remete ao que está socialmente posto (interdiscurso; ORLANDI, 2013; PÊCHEUX, 2014) acerca de um vestuário considerado apropriado para as mulheres, não devendo deixar o corpo a mostra - aliás, o Esquecimento Número 2 (ORLANDI, 2013; PÊCHEUX, 2014) pode ser exemplificado neste ponto visto que a E2 utilizou a palavra "fechada" e não qualquer outra, como, por exemplo, "confortável".

Saffioti (2011) argumenta que mulheres são socializadas de modo a desempenhar comportamentos dóceis, conciliadores e sensíveis, enquanto os homens são incentivados a desempenhar comportamentos agressivos, perigosos e corajosos. A seguir, são apresentadas algumas articulações e efeitos de sentido nos discursos referentes às condutas consideradas tipicamente femininas (amorosa, educada, inteligente e teimosa) nos seguintes OD (6 a 10):

OD 6:

Pergunta: Você acha que tem alguma diferença entre ter aula com professor ou com professora?

A minha... irmã, ela fala que... ela já teve um... professor... homem que não ensinava tão bem. Já dois. Ela preferia mulher. Parece que ensina melhor ela falou. (E5)

Pergunta: O que você acha disso?

Disso?... Que que eu acho? Eu acho que é... verdade. Por causa que... é... os homem não é tão inteligente igual as mulher. (E5) 
DE TILIO, Rafael; CAMPOS, Maria Teresa de Assis; NASCIMENTO, Luara Daisy. Efeitos de sentido sobre sexualidade e gênero nos discursos de crianças escolares.

\section{OD 7:}

Pergunta: Você acha que meninos e meninas são diferentes?

São. (E6)

\section{Pergunta: Como?}

Menina é... mais inteligente do que os homens né. É... menina veste diferente de que menino... Hm... (pausa) Menina é um pouquinho mais custosa. (E6)

\section{OD 8:}

Pergunta: O que você acha dos professores e dos funcionários da escola?

Muito bons, muito legais, muito educados. (E4)

Pergunta: Como é isso?

Porque... as minhas professoras, elas são muito legais, educadas... amorosas... são muito, muito boas. (E4)

OD 9:

Pergunta: Me conta um pouquinho o que você aprende na escola

É... muita coisa. (E2)

Pergunta: Me conta algumas coisas

(pausa) Eu tenho que... na escola, eu tenho que ser educada. Na escola... não pode maltratar os colegas... mais coisas. (E2)

OD 10:

Pergunta: Você acha que existem brincadeiras só para meninos, brincadeiras só para meninas e brincadeiras para os dois?

Eu te garanto muito que tem pros dois. Muitas brincadeiras pros dois. (E7)

Pergunta: Quais brincadeiras você acha que são pros dois?

Pique-pega, pique-esconde. (E7)

Pergunta: Por que você acha que são essas?

Porque... pique-pega não machuca. E pique-esconde também não. (E7) 
DE TILIO, Rafael; CAMPOS, Maria Teresa de Assis; NASCIMENTO, Luara Daisy. Efeitos de sentido sobre sexualidade e gênero nos discursos de crianças escolares.

Ao descrever as professoras E4 utilizou palavras que rememoram o universo de características consideradas adequadas ao feminino (“educadas" e "amorosas"), sendo estas as características que as qualificam como boas profissionais. E2 ainda relatou que na escola tem que ser "educada", podendo nisso haver uma dupla relação de sentido: obrigatoriedade de aprender (educação formal) e obrigatoriedade de conformação (postura, conduta e modo de agir esperados da feminilidade). O E7 apontou para uma relação de sentido que destacou que as brincadeiras partilhadas entre meninos e meninas devem ser as que não machucam, o que aparentemente se sustenta na suposição de que meninas são frágeis e sensíveis.

Ainda é possível notar no OD 11 da E4 condutas tradicionalmente consideradas femininas e masculinas de forma a relacionar suas preferências por determinadas brincadeiras:

OD 11:

Pergunta: Você acha que existe brincadeira só pra menino, brincadeira só pra menina e brincadeira pros dois?

Eu acho, porque... eu acho que menina não fica tão boa pra jogar futebol e menino não fica tão bom pra brincar de boneca. Uma brincadeira que fica bom pra brincar os dois: queimada. Que aí dá pra brincar tanto com menino quanto com menina. (E4)

Pergunta: Por que você acha que algumas brincadeiras 'não fica bom' pra menino ou menina?

Porque não combina com menino... não combina com menina. (E4)

Pergunta: De que forma não combina?

Porque, assim... geralmente os meninos são mais fortes que as meninas. Aí... que eles, derrubar uma, quer dizer, que eles tão brincando lá junto de futebol, que um menino vim muito forte e... tipo que empurrar uma menina assim sem querer, ela vai cair no chão e pode machucar. Agora... a menina não vai ter a força de jogar o menino no chão. Igual de boneca assim... Eu acho que não tem nada a ver um menino brincar de boneca. Mas isso não tem nada a ver, só que... (E4)

Pergunta: O que você acha que não tem nada a ver?

Eles brincar de boneca, porque... boneca é mais feito pra menina, né. Mas que se eles quiser eles pode, né. (E4)

E4 corroborou com o sentido acerca da fragilidade feminina, bem como da força atrelada à masculinidade. Além disso, relatou que "não fica bom" ou "não combina" determinado tipo de conduta no brincar que contrarie as expetativas de gênero. Assim, é possível notar o equívoco e 
DE TILIO, Rafael; CAMPOS, Maria Teresa de Assis; NASCIMENTO, Luara Daisy. Efeitos de sentido sobre sexualidade e gênero nos discursos de crianças escolares.

uma ambivalência no momento em que a E4 referiu a possibilidade (via estranhamento) de um menino brincar com bonecas ao mesmo tempo em que negou esse estranhamento ("mas isso não tem nada a ver, só que..."; "se eles quiser eles pode, né”; "boneca é mais feito pra menina”; “não tem nada a ver um menino brincar de boneca”). Logo, vê-se a contradição entre o que está tradicionalmente posto (meninos não brincam de boneca), ao passo que há no interdiscurso a crítica a este sentido, levando-a a um impasse resolvido pelo reestabelecimento dos aspectos tradicionais de gênero.

\subsection{Processo Discursivo}

No processo discursivo serão relacionadas as FD a uma exterioridade em comum, ou seja, a uma FI específica a qual pertencem - os efeitos de sentidos aludem aos tradicionalismos de sexo e gênero pautados em uma sociedade heteronormativa e patriarcal. De maneira resumida, é possível considerar que nas FD há sentidos marcados por preferências, habilidades, formas de socializar e condutas pautadas em padrões e normas cristalizados em convenções tradicionalistas e binárias de sexo e gênero.

Em geral, evocou-se que meninos e meninas têm preferências por brincadeiras específicas de acordo com o gênero, bem como habilidades e interesses inatos. A socialização estaria atrelada às formas de identificação via preferências ou condutas comuns entre meninos e meninas que delimitariam o que é adequado e apropriado ou não ao universo feminino e masculino, seja em sua expressão física (anatomia), performativa (vestuário), subjetiva (traços de personalidade) ou atitudinal (comportamentos) pautados nas diferenciações de gênero. Assim, percebe-se a influência do Esquecimento Número 1 de forma que estes discursos são considerados opiniões originadas e formuladas por seus enunciadores - contudo, como será debatido, elas compreendem uma expressão pautada numa Formação Ideológica (ORLANDI, 2013; PÊCHEUX, 2014).

Acerca da referida sociedade heteronormativa e patriarcal Foucault (2014) discorre sobre o dispositivo da sexualidade para explicar sobre uma rede de saberes e poderes estabelecida que atua produzindo normatizações sobre os corpos, distinguindo e separando o normal e o anormal em relação à sexualidade e aos gêneros. A sociedade contemporânea configura-se, então, de maneira hierarquizada em modelos e padrões no que se refere às relações entre os gêneros. Nesse sentido, há valores, concepções, determinações e normatizações amparadas em um determinado contexto sociohistórico que acentua a dominação do masculino sobre o feminino, estabelecendo 
DE TILIO, Rafael; CAMPOS, Maria Teresa de Assis; NASCIMENTO, Luara Daisy. Efeitos de sentido sobre sexualidade e gênero nos discursos de crianças escolares.

desigualdades refletidas na subjetividade dos sujeitos e na organização social, podendo gerar discriminação e violência (FOUCAULT, 2014). É nesta construção (FI) de sociedade descrita por Foucault que os efeitos de sentidos (discursos) são sedimentados via interdiscurso (ORLANDI, 2013; PÊCHEUX, 2014).

Neste ínterim, há construções cristalizadas nos discursos dos participantes que evidenciaram uma perspectiva binária de sexo e gênero, na qual o gênero estaria decidido e determinado pelo sexo (biológico) - linearidade criticada por Butler (2001, 2015). Nesta pesquisa foi possível notar a reprodução da obrigatoriedade entre sexo e gênero reforçando o normativo binário. Foi possível notar reiteradas formulações parafrásticas (ORLANDI, 2013; PÊCHEUX, 2014) apontando para condutas e características consideradas próprias da feminilidade e da masculinidade. A respeito disso Beauvoir (2016) argumenta sobre a construção social do gênero que em nossa sociedade estigmatiza a mulher situando-a subordinada ao homem.

Reitera-se que esses discursos pautados na FI supracitada invadem e são replicadas no contexto escolar - condição de produção dos discursos dos sujeitos interlocutores participantes desta pesquisa (ORLANDI, 2013; PÊCHEUX, 2014). Assim, tem-se este contexto enquanto parte constituinte da subjetividade das crianças - pois há outros contextos - logo, enquanto espaço que pode reforçar os tradicionalismos de gênero. Isso é significativo pelo fato de que estes efeitos de sentido sobre sexualidade e gênero podem contribuir para a manutenção das desigualdades entre os sexos e gêneros. Louro (2003) destaca que as estratégias de organização e os procedimentos das disciplinas escolares são exercícios de poder em relação ao gênero, etnia, classe e/ou sexualidade. Assim, as ferramentas de ensino (currículos, regulamentos, instrumentos de avaliação, entre outros) hierarquizam, subordinam e diferenciam os sujeitos (LOURO, 2003).

A partir dos resultados desta pesquisa pode depreender que práticas e discursos sobre gênero e sexualidade não necessariamente são formulados pela/na escola, mas eles invadem seus espaços e relações.

\section{Considerações finais}

Com a finalidade de identificar alguns dos efeitos de sentido sobre sexualidade e gênero presentes num determinado contexto escolar, realizou-se uma análise de discurso que apontou para preferências e habilidades, socializações e condutas pautadas em determinismos e 
DE TILIO, Rafael; CAMPOS, Maria Teresa de Assis; NASCIMENTO, Luara Daisy. Efeitos de sentido sobre sexualidade e gênero nos discursos de crianças escolares.

tradicionalismos de sexo (aspectos biológicos) e gênero (aspectos culturais) interpelados por uma expressão ideológica heteronormativa e patriarcal.

Intentou-se produzir uma compreensão acerca dos discursos proferidos num determinado contexto escolar de modo a discutir sentidos sedimentados a partir de uma ideologia dominante, bem como possibilitar o reconhecimento de condições de produção e reprodução destes discursos por parte dos seus produtores.

Ainda que a partir desta experiência em um contexto escolar específico, essa pesquisa espera oferecer reflexões que contribuam para possibilidades de discussões de gênero e sexualidade no âmbito escolar, oferecendo suporte e oportunizando esclarecimentos para ações que visem a equidade de gênero dentro e fora da escola. Neste sentido, reconhece-se a necessidade de realização de outras investigações com mais participantes sobre as questões de gênero e sexualidade no contexto escolar a partir da perspectiva dos seus diversos a(u)tores.

\section{Referências}

ANDRADE, L. B. P. Educação infantil: discurso, legislação e práticas institucionais. São Paulo: UNESP; Cultura Acadêmica, 2010.

AVILA, A. H.; TONELI, M. J. F.; ANDALÓ, C. S. A. Professores/as diante da sexualidade-gênero no cotidiano escolar. Psicologia em Estudo, Maringá, v. 16, n. 2, p. 289-298, jun. 2011.

BEAUVOIR, S. O segundo sexo: fatos e mitos. Rio de Janeiro: Nova Fronteira, 2016.

BICHARA, I. D. Brincadeiras de meninos e meninas: segregação e estereotipia em episódios de faz-deconta. Temas em psicologia, Ribeirão Preto, v. 9, n. 1, p. 19-28, abr. 2001.

BORGES, R. O.; BORGES, Z. N. Pânico moral e ideologia de gênero articulados na supressão de diretrizes sobre questões de gênero e sexualidade nas escolas. Revista Brasileira de Educação, Rio de Janeiro, v. 23, n.26, p. 1-23, jul. 2018.

BOYD, D.; BEE, H. A criança em crescimento. Porto Alegre: Artmed, 2011.

BUTLER, J. Corpos que pesam: sobre os limites discursivos do sexo. In: LOURO, G. L. (org.). O corpo educado: pedagogias da sexualidade. 2. ed. Belo Horizonte: Autêntica, 2001. p. 151-172.

BUTLER, J. Problemas de gênero: feminismo e subversão da identidade. Rio de Janeiro: Civilização Brasileira, 2015.

CAMPOS, L. M. L. Gênero e diversidade sexual na escola: a urgência da reconstrução de sentidos e de práticas. Ciência \& Educação, Bauru, v. 21, n. 4, p. 1-4, dez. 2015.

CÉSAR, M. R. A. Gênero, sexualidade e educação: notas para uma "epistemologia”. Educar, Curitiba, v. 35, n. 1, p. 37-51, dez. 2009.

CORDAZZO, S. T. D.; VIEIRA, M. L. Caracterização de brincadeiras de crianças em idade escolar.

Psicologia: Reflexão e Crítica, Porto Alegre, v. 21, n. 3, p. 365-373, ago. 2008. 
DE TILIO, Rafael; CAMPOS, Maria Teresa de Assis; NASCIMENTO, Luara Daisy. Efeitos de sentido sobre sexualidade e gênero nos discursos de crianças escolares.

FOUCAULT, M. História da sexualidade I: a vontade de saber. 19. ed. Rio de Janeiro: Graal, 2014. GOMES, A. M. T. Do discurso às formações ideológica e imaginária: Análise de discurso segundo Pêcheux e Orlandi. Revista Enfermagem UERJ, Rio de Janeiro, v. 15, n. 4, p. 555-562, out./dez. 2007. LEITE, L. G.; FEIJÓ, J. P.; CHIÉS, P. V. Qual o gênero do brincar? Aprendendo a ser “menino" ... Aprendendo a ser "menina". Motrivivência, Florianópolis, v. 28, n. 47, p. 210-225, maio 2016.

LOURO, G. L. Gênero, sexualidade e educação: uma perspectiva pós-estruturalista. 6. ed. Petrópolis: Vozes, 2003.

MAIA, A. C. B. Identidade e papéis sexuais: uma discussão sobre gênero na escola. In: MAIA, A. C. B.; MAIA A. F. (orgs.). Sexualidade e infância. Bauru: CECEMCA/UNESP, 2005. p. 32-40.

MAIA, A. C. B. et al. Educação sexual na escola a partir da psicologia histórico-cultural. Psicologia em Estudo, Maringá, v. 17, n. 1, p. 151-156, mar. 2012.

MARTINS, S. O. Análise do discurso. Revista Científica da Ajes, Juína, v. 2, n. 3, p. 1-7, set. 2011.

MISKOLCI, R.; CAMPANA, M. "Ideologia de gênero": notas para a genealogia de um pânico moral contemporâneo. Sociedade e Estado, Brasília, v. 32, n. 3, p. 725-748, dez. 2017.

MONTEIRO, M. V. P. A construção identitária nas aulas de educação física. Revista Brasileira de Educação, Rio de Janeiro, v. 22, n. 69, p. 339-359, set. 2017.

MOSCONI, N. Escola mista e igualdade entre os sexos no contexto francês. Educação e Realidade, Porto Alegre, v. 39, n. 1, p. 221-239, mar. 2014.

ORLANDI, E. P. Análise do discurso: princípios e procedimentos. Campinas: Pontes, 2013.

PÊCHEUX, M. Semântica e discurso: uma crítica à afirmação do óbvio. Campinas: Unicamp, 2014.

PYLRO, S. C.; ROSSETTI, C. B. Atividades lúdicas, gênero e vida adulta. Psico-USF, Itatiba, v. 10, n. 1, p. 77-86, jun. 2005.

RIBEIRO, J. S. B. Brincadeiras de meninas e de meninos: socialização, sexualidade e gênero entre crianças e a construção social das diferenças. Cadernos Pagu, Campinas, n. 26, p. 145-168, jun. 2006.

SAFFIOTI, H. I. B. Gênero, patriarcado, violência. 2. ed. São Paulo: Editora Fundação Perseu Abramo, 2011.

SOUSA, L. A. B.; GRAUPE, M. E. Gênero e Políticas Públicas de Educação. In: SIMPÓSIO GÊNERO E POLÍTICAS PÚBLICAS. 3., 2014, Londrina, Londrina, PR. Anais [...]. Londrina, PR: Universidade Estadual de Londrina, 2014. p. 1-8. 